\title{
Pregnancy with Complete Hydatidiform Mole, Coexisting with a Normal Living Fetus: Case Reports
}

\author{
Diaulas Costa Ribeiro, ${ }^{1,2}$, Rodrigo Nascimento Avellar Fonseca, \\ Cristina Carolina Silva de Almeida ${ }^{3}$, Júlia de Andrade Figueiredo ${ }^{2}$, \\ Bruna Ribeiro Resende ${ }^{2}$, Bruna Gomes Ribeiro²
}

${ }^{1}$ The Law School, Catholic University of Brasilia, Brasilia-DF, Brazil

${ }^{2}$ The Medical School, Catholic University of Brasilia, Brasilia-DF, Brazil

${ }^{3}$ The Nursing Course, Catholic University of Brasilia, Brasilia-DF, Brazil

Email:diaulas@diaulas.com.br

How to cite this paper: Ribeiro, D.C., Fonseca, R.N.A., de Almeida, C.C.S., Figueiredo, J. de A., Resende, B.R. and Ribeiro, B.G. (2017) Pregnancy with Complete Hydatidiform Mole, Coexisting with a Normal Living Fetus: Case Reports. Open Access Library Journal, 4: e4088. https://doi.org/10.4236/oalib.1104088

Received: October 30, 2017

Accepted: November 26, 2017

Published: November 29, 2017

Copyright $(2017$ by authors and Open Access Library Inc.

This work is licensed under the Creative Commons Attribution International License (CC BY 4.0).

http://creativecommons.org/licenses/by/4.0/

\section{(c) (†) Open Access}

\begin{abstract}
This is a case study of twin pregnancy, going through a complete hydatidiform mole with living fetus. The pregnant woman had a previous partial hydatidiform mole, diagnosed and confirmed five months before the pregnancy which is the subject of this study. The first suspected diagnosis was made by means of a medical external ultrasound scan, confirmed by other tests, such as the dosage of $\beta$-HCG. Besides the bibliographic review, this study addresses legal aspects of the Brazilian system which does not allow termination of pregnancy in these situations. In this particular case, the living fetus was sacrificed through uterine evacuation, featuring a criminal abortion. For the safety of the medical staff and the pregnant woman herself, there was the need for a special authorization from the Public Prosecution to the medical procedure.
\end{abstract}

\section{Subject Areas}

Gynecology \& Obstetrics

\section{Keywords}

Complete Hydatidiform Mole, Partial Hydatidiform Mole, Twin Pregnancy, Selective Abortion, Abortion, Judicial Power, Public Prosecution

\section{Introduction}

"The hydatidiform mole (HM) is an obstetric complication that can progress 
into malignant behaviour pathology, and gestational trophoblastic disease (GTD) is its most frequent disorder" [1].

This disorder can be complete, characterized by hydropic degeneration of chorionic villi, or partial, exhibiting a population of normal chorionic villi and another one with hydropic degeneration [2].

According to Chen [3] and Sak et al. [4], quoted by Varela et al. [5], the twin pregnancy developing a living fetus and $\mathrm{HM}$ in coexistence is a rare condition, as shown by its incidence rate: from 1 to 23 cases per 100,000 pregnancies. The HM is associated with clinical adversities, such as anemia, preeclampsia, miscarriage, fetal malformations, proteinuria, hyperthyroidism and respiratory failure, leading the medical procedure, in some cases, into a selective abortion to protect the mother's life [2] [6].

The case reported below refers to a twin pregnancy with simultaneous complete hydatidiform mole (CHM) and living fetus, associated with the risk of maternal death. Such condition imposes that its approach is restricted to not only a medical discussion, but also a legal one, whereas selective abortion in Brazil is formally a crime.

\section{Case Summary}

T.C.N.P., Brazilian, 27 years old, 4 previous pregnancies terminated by 2 miscarriages, 1 vaginal delivery and 1 cesarean section, had a history of embryonic death, diagnosed and confirmed in February 2009 as partial hydatidiform mole (PHM). She was subjected to uterine evacuation by the technique of Manual Vacuum Aspiration (MVA), with monitoring of serum $\beta$-HCG levels, which underwent complete reduction over the next eight weeks to the aforementioned procedure.

In July 2009, she prepared for a new pregnancy, after release from her doctor.

Once she obtained the diagnosis of pregnancy she underwent an external ultrasound scan, the result of which showed the existence of two gestational sacs of different sizes, and the smallest, in serial ultrasound scan, appeared to be a blighted ovum (without development of the embryo), while the other showed a satisfactory evolution for its gestational age. The confirmatory examination of twin pregnancy occurred on August 5, 2009.

Around September 11, the patient felt colicky pelvic pain and had vaginal bleeding, having sought the emergency room of a private hospital in Brasilia (Brazilian Capital), where it was proven she had twin pregnancy with one fetus in gestational age at around nine weeks and a half, and the other showing trophoblastic vesicular changes suggestive of Gestational Trophoblastic Disease (GTD).

After three days, the patient underwent a new ultrasound scan, which confirmed the described changes (Picture 1, Picture 2). 

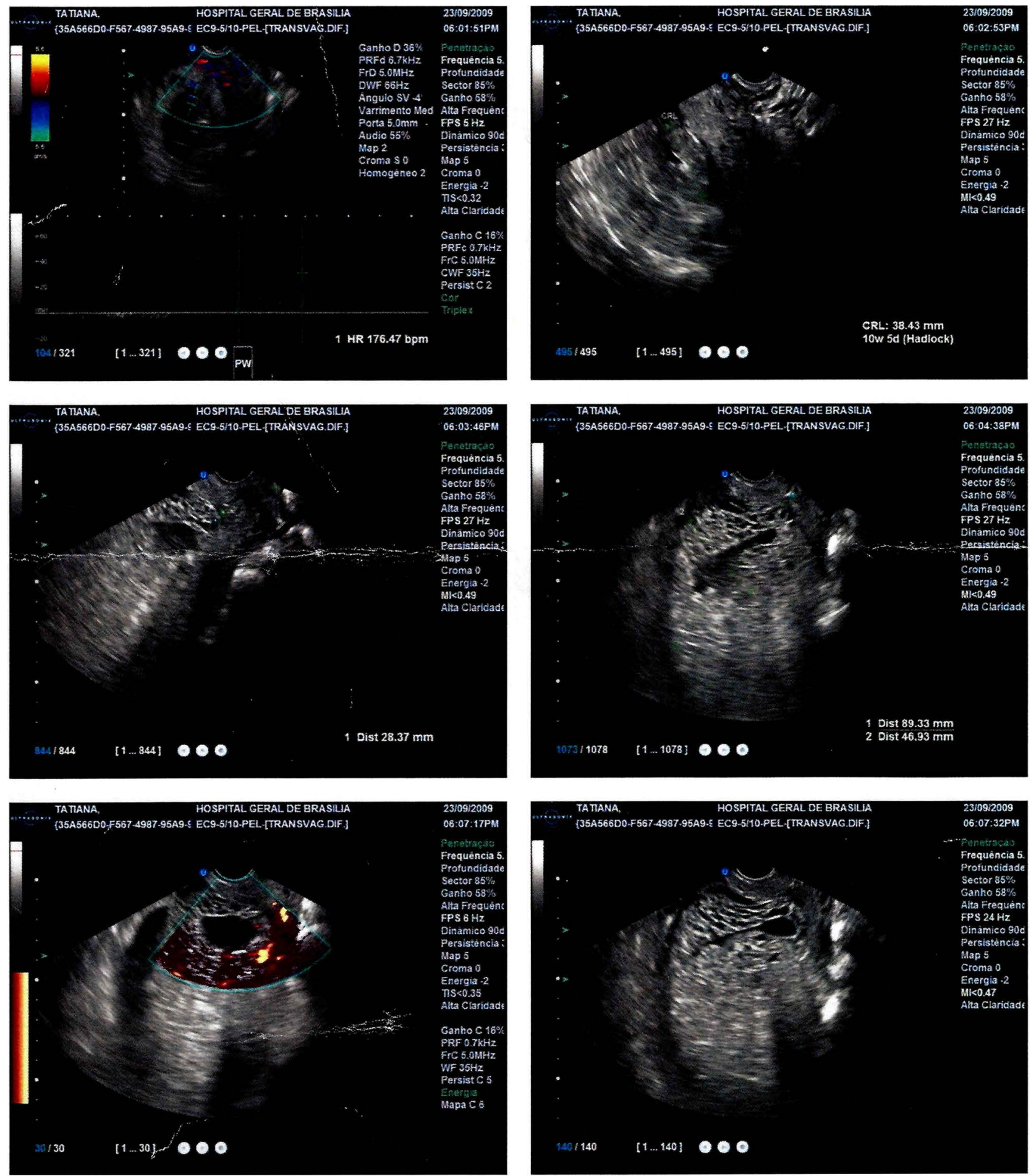

Picture 1. Ultrasound scan picture, part one.

The medical team then proposed the implementation of: 1) chorionic villus sampling in the 11th gestational week, in order to confirm the diagnosis for complete mole. This examination was never performed; 2) X-ray of the chest, which, after all, showed no change; 3) quantitative $\beta$-HCG, which showed results consistent with GTD: 760,000 mIU/mI. 

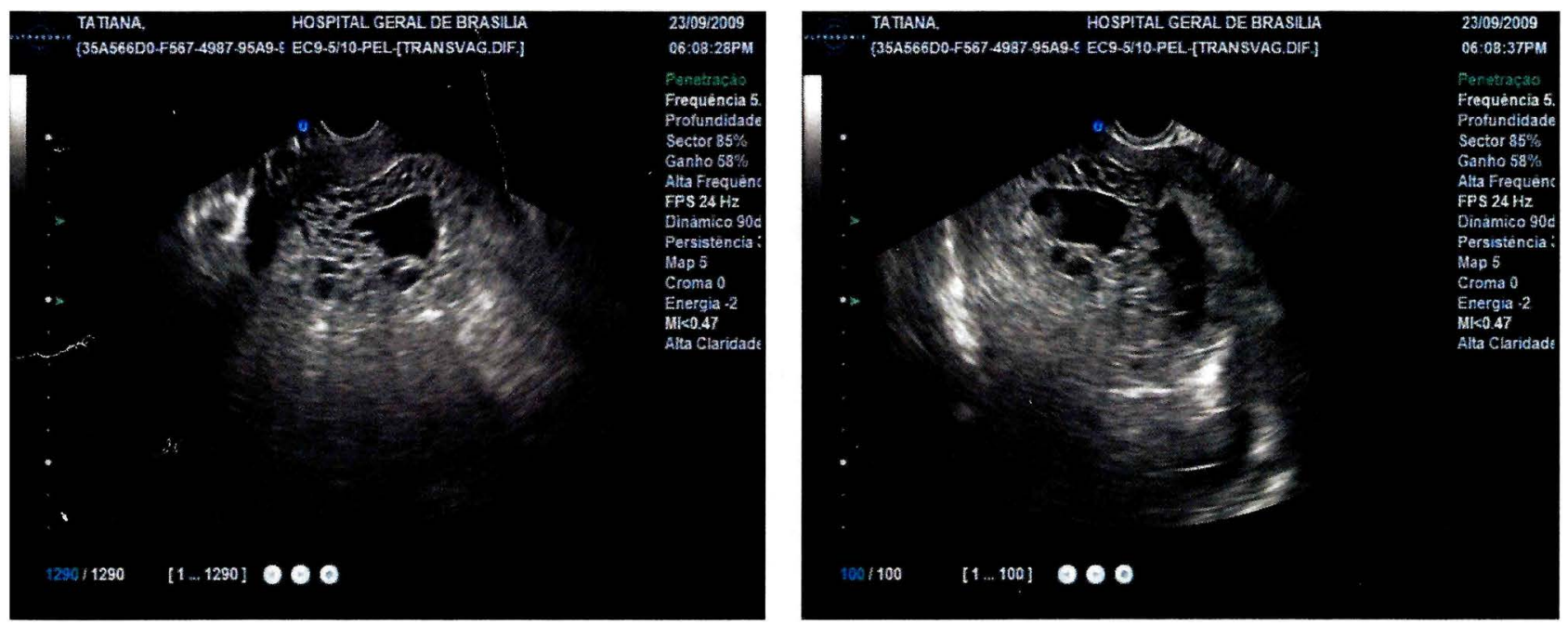

Picture 2. Ultrasound scan picture, part two.

Two days later, with the intensification of the bleeding and persistent pain symptoms, the patient returned to the hospital. She was submitted to another ultrasound scan, which allowed the team to reaffirm the twin pregnancy, with a fetus having the gestational age of ten weeks and six days, and the other with an irregular gestational sac, confirming the suspicions of GTD (Picture 3).

Given this result, the patient was admitted on September 23 for analgesia, hydration, rest and the conducting of new tests, including blood count. The result of the last examination showed an anemic frame with hemoglobin $(\mathrm{Hb})$ of $9.5 \mathrm{mg} / \mathrm{dl}$ (normal female range/nonpregnant: 12.0 - $15.5 \mathrm{mg} / \mathrm{dl}$; pregnant/first trimester: 11.6 - 13.9) and hematocrit (Htc) of 29.4\% (normal female range/nonpregnant: 34.9 - 44.5 percent; pregnant/first trimester: 31 - 41 percent) [7].

Due to the medical severity, with a history of HM, and the high risk of evolution into a trophoblastic tumor, the medical staff indicated uterine evacuation as the most appropriate conduct, that is, the voluntary termination of pregnancy (VTP).

\section{Juridical Issue}

The Brazilian Penal Code (PC) only allows abortion in two situations: life-threatening to the mother, and pregnancy arising from sexual crime. In 2012, the Supreme Court (STF) authorized, under Claim of Breach of Fundamental Precept (ADPF) [8], a third permissive cause: the pregnancy with anencephalic fetus.

Since the $90 \mathrm{~s}$, however, judges and prosecutors (members of The Public Prosecution, as known as Public Ministry) authorized the therapeutic abortion (TA) of anencephalic fetuses at the request of pregnant woman. Alternatives to the restrictive system of PC, as of 1942, were created through jurisprudential precedents. 


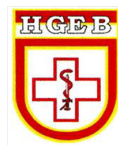

Patient: TCNP

Physician: DR. MARCELO COSTA CRONEMBERGER MARQUES

Registry: 002562

Health Plan: FUSEX

Age : 27 years and 7 months

Date : 23/09/2009

\section{OBSTETRIC ULTRASOUND $1^{\text {st }}$ TRIMESTER/QUARTER (ENDOVAGINAL)}

EQUIPMENT:

Examination performed in bi-dimensional mode with vaginal dynamic equipment at $7.50 \mathrm{Mhz}$ frequency.

BLADDER:

Anechoic content, smooth and well-defined walls.

VAGINA:

Acoustically normal.

UTERUS:

F. S. D.: (Retrouterine Space, also known as the pouch of Douglas).

Free

GENERAL REMARKS:

Featuring increased uterus volume with 2 gestational sacs being the more inferior and right side with vesicular heterogeneous aspect next to 10 (internal orifice) the uterine neck (uterine neck measures 28 $\mathrm{mm}$ ) this measuring $8 \mathrm{~cm}$ in the greatest diameter, giving aspect of GTD. The second gestational sac is more superior and more to the left with fetus measuring $38 \mathrm{~mm}$ craniocaudal diameter with FHB (Fetal Heart Beat) of 172 bpm

DIAGNOSTIC HYPOTHESIS:

Twin Pregnancy with 1 fetus Ig 10 weeks and 6 days and another with irregular gestational sac suggestive of GTD (Gestational Trophoblastic Disease)

Picture 3. Ultrasound scan medical report.

In retaliation to these permits, social organizations against abortion (pro-life associations) started resorting to the Judicial Power, using habeas corpus as a legal instrument in favour of the fetus to prevent the pregnancy interruption in these cases. An opposed movement for the right to decide (pro-choice) also began using habeas corpus as a preventive means to ensure the doctor's and the pregnant woman's freedom to perform the termination of pregnancy in these situations, hindering probable lawsuits and even arrests. Statistically, the authorization for abortion prevailed, and was later confirmed by the Brazilian Supreme Court.

In addition to the pregnancy of anencephalic fetuses, the request for authorization to judges or The Public Prosecution to carry out VTPs in situations such as T.C.N.P.'s was extended.

Thus, facing the required termination of molar pregnancy, with the inevitable sacrifice of the viable fetus, on September 25, 2009, Friday, a preventive habeas corpus was filed, submitted to a Criminal Judge of Brasilia. The purpose was, through demonstrating the absence of crime, protecting the patient and the 
medical staff from a lawsuit, hindering the effect of art. 124 (abortion consented by the pregnant woman) and art. 126 (abortion practiced with the pregnant woman's consent), both from the Penal Code. This habeas corpus was forwarded to The Public Prosecution which, for over 18 years, is the body responsible for analysing and authorizing applications for abortion in situations like this, in the Brazilian's Capital.

Facing this imminent risk to the mother's life, the same day, at $8: 30 \mathrm{pm}$, the VTP was allowed by the Public Prosecutor in charge.

\section{Discussion}

The establishment of the GTD's epidemiological profile is still inaccurate, due mainly to difficulties in the collection process of reliable data [9]. However, there have been effective studies in demonstrating the differences that characterize the affected population, and the most prevalent HM concern Eskimos and Hispanics, indigenous ancestry and African Americans, as well as several Asian populations [9].

The reason for such distribution is not yet understood. However, it has been known that in Southeast Asia the incidence rates of choriocarcinoma, a serious complication of GTD [2], reach values up to nine times (9.2:40,000 pregnancies) higher than the rates in Europe and North America (1:30,000 - 40,000) [9] [10]. Andrade [1] indicates that, from the individual viewpoint, past records of HM increase the risk for the subsequent pregnancies up to five times, confirming the risk to which the patient T.C.N.P. was subjected, reinforcing the justified decision of The Public Prosecution.

When there is a living fetus in a placenta with molar degeneration, it is necessary to question two possibilities: whether this is a PHM with triploid fetus, or a twin pregnancy with a living fetus in coexistence with a complete mole (TPCHM, Twin Pregnancy with a Complete Hydatidiform Mole) [11].

The use of the karyotype is directly related to the histopathology of the molar tissue. Considering the two types of HM, it is noted that in the case of the CHM the karyotype appears as diploid, having only paternal genes.

The trophoblastic change results from the fertilization of secondary oocyte, without active nucleus, by a diploid spermatozoid [1]. The PHM, in turn, usually is triploid or, more rarely, tetraploid, as a result of normal secondary oocyte fertilization, with active nucleus, by two spermatozoids or one diploid spermatozoid [1]. The resulting foetuses of these types of fertilization display abnormalities, such as asymmetries in intrauterine growth and a series of malformations [12].

Upon detecting molar pregnancy, the usually adopted procedure is abortion and uterine evacuation, to prevent complications [2]. Even after counselling, some patients may choose to continue pregnancy, although they should be prepared for abortion, if any severe mishaps affect their lives, even to the point of exposing them to the risk of death. 
Secondary complications of molar pregnancy are diverse and affect both the fetus and the mother. They progress from frequent hyperemesis scenarios to preeclampsia, thyroid storm and trophoblastic embolism [1] [12]. Intense vaginal bleeding also worries the medical team because it is an emerging risk of maternal death by hypovolemic shock.

Yela et al. [11], in a literature review of 29 studies, found the description of 159 cases of TPCHM (Twin Pregnancy with a Complete Hydatidiform Mole), and of those, only 56 (35\%) completed the pregnancy with a living fetus. Most of these pregnancies presented complications such as preeclampsia and persistent trophoblastic disease.

Patients with PHM suffer symptoms similar to an incomplete or missed abortion, highlighting the need for uterine curettage. But the diagnosis of PHM is usually obtained by posterior histological evaluation [1].

For uterine evacuation, it is recommended the vacuum aspiration that must be completed with curettage of the uterine walls, in order to confirm complete removal of the molar material [2]. Knowledge of techniques used for uterine evacuation is essential for the best procedure in each case.

After treatment of the hydatidiform mole, the evaluation is done by the weekly dosage of $\beta$-HCG, which should be negative (below $5 \mathrm{mIU} / \mathrm{mL}$ ). It is advisable making up to three consecutive weekly dosages, besides laboratory follow-through by monthly and annual dosages of the hormone [1].

Reports of clinical cases of hydatidiform mole are of utter importance for the construction of clinical reasoning and the choosing of the best procedure for each patient, because, despite their low incidence, these cases involve a pregnancy which, in most cases, is desired and planned. A bio-psycho-social approach of the patient is necessary because the interruption of a desired pregnancy is harder.

The patient T.C.N.P., in her medical history and in the subsequent scenario, showed symptoms of abortion, such as vaginal bleeding. The progression of her clinical frame, with intensification of pelvic pain, into colic, the vaginal bleeding, and the anemia, led the medical staff to hospitalize her. Facing the result of the ultrasound scan, suspecting of TPCHM (Twin Pregnancy with a Complete Hydatidiform Mole), it was determined the realization of the fetal karyotype and the cytogenetic preparation to confirm diagnosis. Moreover, the chest X-ray was recommended in order to verify the presence of breathing complications [1].

In the case of T.C.N.P., the occurrence of PHM and CHM in a very short time interval-only five months-contributed to the advice for interrupting her pregnancy. She was informed of the risks she would undergo if she chose to follow through, as well on what concerns the high probability of progression into a trophoblastic tumour [13], as evidenced in the literature.

\section{Conclusions}

On 26 September 2009, the patient displayed a mild degree of anxiety, with im- 
provement of pain symptoms still early in the morning, controlled with dipyrone, and moderate vaginal bleeding. On the evening of that same day, under her free and aware consent, the VTP was held.

The technique was MVA, followed by curettage.

On September 27, at 3:30 pm, T.C.N.P. was discharged with medical recommendations.

\section{Acknowledgements}

The authors render thanks to: T.C.N.P., the Patient;

Dr. André Ricardo Meinicke, MD;

Dr. Evandro de Oliveira, MD;

Dra. Kelle Lobato Moreira, Lawyer;

Dr. Marcelo Costa Cronemberger Marques, MD;

Dr. Paulo de Sousa Montenegro, MD.

\section{References}

[1] Andrade, J.M. (2009) Hydatidiform Mole and Gestational Trophoblastic Disease. Revista Brasileira de Ginecologia e Obstetrícia, 31, 94-101.

[2] Péret, F.J.A., Côrrea Júnior, M.D., Viggiano, M.G.C. and de Paula, L.B. (2011) Bleeding in the First Half of Pregnancy. In: Côrrea, M.D., Melo, V.H., Aguiar, R.A.L.P. and Côrrea Júnior, M.D., Eds., Basic Practices in Obstetrics, 14th Edition, Coopmed, Belo Horizonte, 249-280.

[3] Chen, F.P. (1997) Molar Pregnancy and Living Normal Fetus Coexisting until Term: Prenatal Biochemical and Sonographic Diagnosis. Human Reproduction, 12, 853-856. https://doi.org/10.1093/humrep/12.4.853

[4] Sak, M.E., Soydinc, H.A., Evsen, M.S., Sak, S. and Firat, U. (2012) Diploid Karyotype Partial Mole Coexisting with Live Term Fetus. Case Report and Review of the World Literature. Ginekologia Polska, 83, 789-791.

[5] Varela, S.T., Palacios, M.N.C., Roche, M.I.M., Hoffner, K.A. and Díez, J.L.D. (2015) Pregnancy with Complete Hydatidiform Mole, Coexisting with a Normal Living Fetus: Clinical Case, with Bibliographic Review. Progresos de Obstetricia y Ginecología, 58, 287-290.

[6] Lima, T.P. (2000) Gestational Trophoblastic Disease. In: Neme, B., Ed., Basic Obstetrics, 2nd Edition, Sarvier, São Paulo, 592-608.

[7] Abbassi-Ghanavati, M., Greer, L.G. and Cunningham, F.G. (2009) Pregnancy and Laboratory Studies: A Reference Table for Clinicians. Obstetrics \& Gynecology, 114, 1326-1331. https://doi.org/10.1097/AOG.0b013e3181c2bde8

[8] Federal Supreme Court of Brazil (2012) ADPF 54. Rapporteur: Justice Marco Aurelio. Judged on Apr. 12, 2012. http://stf.jus.br/portal/jurisprudencia/listar

[9] Lurain, J.R. (2010) Gestational Trophoblastic Disease I: Epidemiology, Pathology, Clinical Presentation and Diagnosis of Gestational Trophoblastic Disease, and Management of Hydatidiform Mole. American Journal of Obstetrics \& Gynecology, 203, 531-539. https://doi.org/10.1016/j.ajog.2010.06.073

[10] Smith, H.O., Qualls, C.R., Prairie, B.A., Padilla, L.A., Rayburn, W.F. and Key, C.R. (2003) Trends in Gestational Choriocarcinoma: A 27-Year Perspective. Obstetrics \& Gynecology, 102, 978-987. https://doi.org/10.1097/00006250-200311000-00017 
[11] Yela, D.A., Pinheiro, A., Pinto, J.P.L. and Andrade, L. (2011) Twin Pregnancy with Complete Hydatidiform Mole and Living Fetus. Jornal Brasileiro de Patologia e Medicina Laboratorial, 47, 165-170. https://doi.org/10.1590/S1676-24442011000200012

[12] Lavanya, R., Hebbar, S., Shyamala, G., Adiga, P. and Anjali, M. (2014) Twin Pregnancy with Hydatidiform Mole and Co-Existent Live Fetus: Lessons Learnt. Malaysian Journal of Medical Sciences, 21, 61-64.

[13] Steller, M.A., Genest, D.R., Bernstein, M.R., Lage, J.M., Goldstein, D.P. and Berkowitz, R.S. (1994) Natural History of Twin Pregnancy with Complete Hydatidiform Mole and Co-Existing Fetus. Obstetrics \& Gynecology, 83, 35-42.

Submit or recommend next manuscript to OALib Journal and we will provide best service for you:

- Publication frequency: Monthly

- 9 subject areas of science, technology and medicine

- Fair and rigorous peer-review system

- Fast publication process

- Article promotion in various social networking sites (LinkedIn, Facebook, Twitter, etc.)

- Maximum dissemination of your research work

Submit Your Paper Online: Click Here to Submit

Or Contact service@oalib.com 